
\title{
3 Research Square \\ Determination of Sex Ratio In Bovine Semen Using SYBR Green Real-Time PCR
}

\section{Vemula Harshini ( $\square$ harshinivemula18@gmail.com )}

Department of Animal Genetics and Breeding https://orcid.org/0000-0001-9484-3444

\section{S.M.K. Karthickeyan}

Department of Animal Genetics and Breeding

\section{P. Kumarasamy, K.G}

Madras Veterinary College

\section{Tirumurugaan}

Tamil Nadu Veterinary and Animal Sciences University

\section{Jeevan}

Department of Animal Genetics and Breeding

\section{Research Article}

Keywords: Bovine, Sex ratio, SYBR green assay, X-enriched semen

Posted Date: January 7th, 2022

DOI: https://doi.org/10.21203/rs.3.rs-1154594/v1

License: (c) (1) This work is licensed under a Creative Commons Attribution 4.0 International License. Read Full License 


\section{Abstract}

A SYBR green real-time PCR assay was developed to find out the sex skewness in bovine sex-sorted semen samples. The qPCR assay of PLP and SRY genes revealed the mean values of X-and Y-bearing spermatozoa as $50.24 \pm 0.65$ and $49.75 \pm 0.62$ per cent in unsorted, and $91.80 \pm 0.79$ and $8.20 \pm 0.73$ per cent in X-enriched semen samples respectively.. The amplification efficiencies of the PLP and SRY primers were 99.25 and 98.03 per cent respectively. The method was validated by a series of repeatability and reproducibility assays which revealed low co-efficients of variations as 2.19 and 3.12 per cent respectively Thus becoming a reliable and inexpensive tool to evaluate the sorted semen on routine basis and validation of other sperm sexing technologies.

\section{Introduction}

The main aim of a breeder is to increase the genetic potential to the maximum level and to produce a desired off-spring under optimal conditions (Pindaru et al., 2016). The scientific approach for the preselection of the sex of off-spring was started in 20th century (Seidel, 2012). Among several conventional techniques such as albumin gradient, swim-up, percoll density gradient, free flow electrophoresis, $\mathrm{H}-\mathrm{Y}$ antigen and sorting based on volumetric differences, flow cytometry effectively sorted the $\mathrm{X}$ - and $\mathrm{Y}$ chromosome bearing spermatozoa. This method is mainly based on the fact that X-bearing (female) spermatozoa contains 3.8 per cent more DNA than Y-bearing sperm (Johnson, 2000). Flow cytometric separation of spermatozoa was first done by Johnson et al. (1989) in rabbits. Later the technique was used successfully in several species (Johnson, 2000; Seidel and Garner, 2002; Maxwell et al., 2004; Lu et al., 2007; Liang et al., 2008).

The efficiency and success of artificial insemination with sorted semen depends on the accuracy of sexing of the spermatozoa (Pindaru et al., 2016) and high sorting accuracy is the pre-requisite for wide spread use of sexed semen (Habermann et al., 2005). The purity of sexed semen is usually verified by flow cytometric reanalysis of the DNA content of semen (Welch and Johnson, 1999). But there is a need for a reliable method, which does not depend on the same instrumentation to prevent the inherent errors of poorly sorted semen (Colley et al., 2008).

Specific DNA sequences on X-and Y-spermatozoa enable the identification of sex of individual sperm and sex ratio of semen samples (Colley et al., 2008; Maya et al., 2013). Several methods were developed to determine sperm sex ratio such as duplex PCR (Colley et al., 2008) or single cell PCR (Yadav et al., 2017), but these techniques were associated with a disadvantage of requirement of large number of individual sperms (Maleki et al., 2013; Yadav et al., 2017). Quantitative real-time PCR (qPCR) technique emerged subsequently with some advanced features for the sex determination of spermatozoa more simply and accurately in pooled semen samples (Maleki et al., 2013). Quantitative PCR allows simultaneous amplification of the DNA and real time monitoring of amount of amplified DNA through reaction cycles. Therefore, the present study was aimed at development and validation of SYBR green real-time PCR assay for the quantification of $X$ and $Y$-bearing spermatozoa in bovine semen samples. 


\section{Materials And Methods}

\section{Semen samples and sperm DNA extraction}

A total of seven unsorted and four X-enriched frozen semen samples were thawed and washed twice with phosphate buffered saline. The sperm pellet was resuspended in $2.5 \mathrm{ml}$ of sperm lysis buffer $(50 \mu \mathrm{l}$ of $1 \mathrm{M}$ Tris- $\mathrm{HCl}, 100 \mu \mathrm{l}$ of $0.5 \mathrm{M}$ EDTA, $100 \mu \mathrm{l}$ of $5 \mathrm{M} \mathrm{NaCl}, 0.1 \mathrm{~g}$ of $4 \%$ SDS and $50 \mu \mathrm{l}$ of $2 \%$ Mercaptoethanol) and $2.2 \mathrm{ml}$ of nuclease free water by vortexing and incubated for 20 minutes at $56^{\circ} \mathrm{C}$ in a water bath. To the suspension, DNAzol (Thermo Scientific, USA) was added, mixed thoroughly and incubated for 2-3 minutes at room temperature. Later, Phenol:Chloroform:Isoamylalcohol (25:24:1) was added, mixed well by vortexing and centrifuged at 11,000 rpm for 10 minutes. The aqueous phase was collected into a separate $2 \mathrm{ml}$ eppendorf tube, added 24:1 ratio of chloroform:isoamylalcohol and mixed throughly by vortexing. After centrifuging at 11,000 rpm for 10 minutes, aqueous phase was collected into a separate tube, equal volume of isopropanol added, centrifuged and the supernatant discarded. Later, the DNA pellet was treated with 70 per cent and absolute alcohol, air-dried and resuspended in $50 \mu$ of TE buffer. The purity and concentration of DNA samples were estimated by gel electrophoresis and spectrophotometry (NanoDrop OneC of Thermo Scientific, USA).

\section{Primers}

Gene specific nucleotide sequence was obtained from NCBI for PLP gene (Genbank Accession No. AJ009913.1) and cattle X-specific PLP primers were designed using Primer-BLAST software. The forward and reverse primer sequences for PLP gene were 3'-ACC AAG GGA AGA GCA GGA AT-5' and 3'-TGC CAA CTT GTA CCC AAA CA-5' respectively. The primers for Y-specific SRY (Sex determining region Y) gene was synthesized as described by Hamilton et al. (2009). PCR amplification was carried out using thermal cycler (Applied Biosystems 2720).

\section{Sybr Green Real-time Assay}

The quantitative PCR was performed with $5 \mu$ of SYBR green mix (Sso A dvanced Universal SYBR Green super mix, Bio-Rad), 3 pmol each of forward primer and reverse primers $(0.3 \mu \mathrm{l}), 70 \mathrm{ng}$ of sperm DNA as template $(1 \mu \mathrm{l})$ and the final volume of reaction was made up to $10 \mu \mathrm{l}$ by nuclease free water. The amplification profile consisted of initial denaturation at $95^{\circ} \mathrm{C}$ for 2 minutes, denaturation at $94^{\circ} \mathrm{C}$ for 30 seconds, annealing at $64^{\circ} \mathrm{C}$ for 30 seconds, extension at $72^{\circ} \mathrm{C}$ for 30 seconds and melt curve at $72-98^{\circ} \mathrm{C}$ with every $0.2^{\circ} \mathrm{C}$ hold for 1 second. The amplified PCR products were checked on 2 per cent agarose gel with 100 bp DNA ladder. The bands were viewed in a GelDoc (Bio-Rad Laboratories Inc., USA) system and the images stored.

\section{Generation Of Standard Curve}


PLP and SRY genes were amplified in a $50 \mu$ I PCR reaction mixture. PCR products were resolved with 2 per cent agarose gel and bands were sliced under UV illumination. The bands were purified from gel with Favrogen gel/PCR purification kit (Favorgen, Taiwan). The concentration of purified PCR products was measured using NanoDrop. The specificity of the PCR product was rechecked with $2 \%$ agarose gel. Using concentration of DNA and product length, copy number per $\mu$ l volume was calculated with online calculator for determining the number of copies of a template (URI Genomics and Sequencing Centre). The concentration of the stock solution was adjusted to $1 \times 10^{6}$ copies. Then, the stock solution was diluted serially by 10 folds to obtain a standard series from $1 \times 10^{6}$ to $1 \times 10^{2}$ copies. A standard curve was constructed with different copy numbers in triplicates. The $\mathrm{C}_{\mathrm{T}}$ values obtained during amplification of each dilution were plotted against logarithm of their template dilution factor. The coefficient of determination $\left(R^{2}\right)$ value obtained from the equation of linear regression line was used to evaluate the qPCR aasay.

\section{Validation of quantitative PCR assay}

Repeatability (intra-assay) means the variability of a method when repeated measures are taken with the same material in a single experiment, while reproducibility (inter-assay) is the variability of a method when repeated measures are taken in different experiments (Maleki et al., 2013). Repeatability was calculated by computing the co-efficients of variation (CV) of X-chromosome (PLP gene) content observed in 20 quantifications of the same unsexed semen sample. Hence, repeatability of the experiment was calculated by conducting 10 repetitions for each dilution $\left(10^{8}\right.$ to $\left.10^{2}\right)$ in two runs of PLP gene. The co-efficients of variation for reproducibility was calculated by performing one measure per run for each dilution $\left(10^{8}\right.$ to $\left.10^{2}\right)$ in 10 runs of PLP gene.

\section{Calculation of copy numbers and percentage of $\mathrm{X}$ - and $\mathrm{Y}$ - spermatozoa}

Copy numbers of unknown samples were calculated by using the formula (Real-Time PCR Application Guide, Bio-Rad)

$\mathrm{Cn}=10^{(\mathrm{ct}-\mathrm{b}) / \mathrm{m}}$

Where, $\mathrm{Cn}=$ copy numbers; $\mathrm{Ct}=\mathrm{Ct}$ value of unknown sample; $\mathrm{b}=$ intercept of standard curve; $\mathrm{m}=$ slope of the standard curve.

Copy numbers for each gene was calculated separately and converted into percentages by using the formula suggested by Parati et al. (2006). A Chi-square test was used to determine whether the observed percentages of $\mathrm{X}$ - and $\mathrm{Y}$-spermatozoa in a semen samples differed significantly from expected sex ratio 1:1. The data were analyzed with IBM SPSS Statistics 20 software.

\section{Results}




\section{Primer specificity analysis}

The primers used for PLP and SRY genes showed uniqueness in amplifying a single PCR product in real time assay as there was neither primer dimer nor non-specific products in reaction. Further analysis by agarose gel confirmed the melt curve analysis. None of the control yielded any signal prior to 30 cycles. Both the primers showed a single melting peak at temperatures $82.20^{\circ} \mathrm{C}(\mathrm{PLP})$ and $84.40^{\circ} \mathrm{C}(\mathrm{SRY})$ as shown in Fig. 1.

\section{Standard curve}

The standard curves obtained showed a linear relationship $\left(R^{2}=0.99\right)$ between logarithm of dilution factors and Ct values for serial template dilutions (Fig. 2). The $\mathrm{Ct}$ values ranged from $8.55\left(1 \times 10^{8}\right)$ to $27.34\left(1 \times 10^{2}\right)$ for PLP gene and $10.38\left(1 \times 10^{8}\right)$ to $28.59\left(1 \times 10^{2}\right)$ for SRY gene (Table 1$)$. The end point of qPCR revealed a clear distinct band in decreasing intensity as a result of serial dilution of the amplicons without formation of any multiple non-specific amplification (Fig. 3).

Table 1. Ct values of standard curves for $P L P$ and $S R Y$ genes for serial template dilutions using quantitative real-time PCR

\begin{tabular}{|llll|}
\hline SI. No. & No. of copies & \multicolumn{2}{l|}{ Ct values } \\
\cline { 3 - 4 } & & $P L P$ & $S R Y$ \\
\hline 1 & $1 \times 10^{2}$ & 27.34 & 28.59 \\
\hline 2 & $1 \times 10^{3}$ & 25.18 & 26.69 \\
\hline 3 & $1 \times 10^{4}$ & 22.26 & 23.04 \\
\hline 4 & $1 \times 10^{5}$ & 19.23 & 20.32 \\
\hline 5 & $1 \times 10^{6}$ & 15.41 & 16.6 \\
\hline 6 & $1 \times 10^{7}$ & 12.22 & 13.03 \\
\hline 7 & $1 \times 10^{8}$ & 8.55 & 10.38 \\
\hline
\end{tabular}

The general linear equations $(y=m x+b)$ obtained for both the genes were $y=-3.183 x+31.33$ for PLP gene

$y=-3.156 x+32.43$ for $S R Y$ gene

Figure 2. Standard curve of (a) PLP and (b) SRY genes 


\section{Repeatability And Reproducibility Assay}

The mean co-efficient of variations resulted from the repeatability and reproducibility assays were 1.45 and 2.69 respectively (Table 2). No significant difference was found among sample dilutions in repeatability and reproducibility assays $(P>0.05)$

\section{Absolute quantification of allosome frequencies}

The mean percentage of $X$ - and $Y$-bearing spermatozoa in unsorted semen samples were $50.24 \pm 0.65$ and $49.75 \pm 0.62$ respectively. The range of $X$ - and $Y$-chromosome bearing spermatozoa varied from 45.94 to 56.70 and 43.29 to 54.05 per cent respectively (Table 3 ).

Table 2. Co-efficients of variation (CV) for the assays of repeatability and reproducibility at different dilutions

of unsorted DNA molecules

\begin{tabular}{|lll|}
\hline No. of copies of DNA molecules/reaction & CV for repeatability (\%) & CV for reproducibility (\%) \\
\hline $1 \times 10^{8}$ & 4.48 & 5.7 \\
\hline $1 \times 10^{7}$ & 1.73 & 2.2 \\
\hline $1 \times 10^{6}$ & 1.95 & 2.03 \\
\hline $1 \times 10^{5}$ & 2.76 & 4.23 \\
\hline $1 \times 10^{4}$ & 1.79 & 3.89 \\
\hline $1 \times 10^{3}$ & 1.4 & 2.31 \\
\hline $1 \times 10^{2}$ & 1.27 & 1.5 \\
\hline Mean & 2.19 & 3.12 \\
\hline
\end{tabular}

The mean values for $X$ - and $Y$-bearing spermatozoa in X-enriched semen samples were $91.80 \pm 0.79$ and $8.20 \pm 0.73$ per cent, ranging from 89.72 to 94.37 and 5.63 to 10.28 respectively (Table 3 ). While the Chisquare statistical test of goodness of fit revealed a significant difference $(P<0.01)$ between the $\mathrm{X}$ - and $\mathrm{Y}$ bearing spermatozoa in the $X$-enriched semen samples and no significant difference between the observed and expected per cent of $\mathrm{X}$ - and $\mathrm{Y}$-spermatozoa in unsorted semen samples with a mean sex ratio equal to $1: 1(50.24: 49.75)$ across all the tested unsorted semen samples.

\section{Discussion}


Real-time quantitative PCR for determination of sperm sex ratio carried out in this study gave an accurate result. PLP and SRY genes were used as gender markers for identification of X-and Y-bearing spermatozoa respectively. Both the genes are present in single copy on $\mathrm{X}$ - and $\mathrm{Y}$-chromosomes, therefore, every single copy of PLP and SRY sequence detected indicated the presence of respective quantities of $X$ and Y-bearing spermatozoa (Tan et al., 2015).

Since all gene sequences for a given species are represented, genomic DNA could serve as universal standard for the absolute quantification of any expressed gene (Yan et al., 2006). In this study, purified PCR products of PLP and SRY genes were used to generate the standard curves. Both the genes gave different Ct values with same gene copy numbers due to differences in the length of gene fragments (Tan et al., 2015). Therefore, two different standard curves were obtained for quantification of $X$ - and $Y$ chromatin bearing spermatozoa. Lower the mean values of co-efficient of variation for repeatability and reproducibility, higher would be reliability of this approach in absolute quantification of $\mathrm{X}$ - and $\mathrm{Y}$ chromatin contents in semen samples.

From the copy numbers of PLP and SRY genes, the quantity of X- (50.24\%) and Y- (49.75\%) chromosome bearing spermatozoa did not differ from 1:1 ratio, which is reported as normal in unsexed mammalian semen samples (Rosenfeld and Roberts, 2004; Luna Estrada et al., 2006; Whyte et al., 2007). According to the standard meiotic model, equal proportion of $\mathrm{X}$ - and $\mathrm{Y}$-bearing spermatozoa are produced in semen (Maleki et al., 2013) and this advantage was utilized to optimize the technique. The sex ratio obtained in unsorted semen samples of this study was also supported by previous reports made by different experiments in sex determination (Piumi et al., 2001, Rens et al., 2001, Revay et al., 2002, Habermann et al., 2005, Parati et al., 2006, Colley et al., 2008, Maleki et al., 2013, Tan et al., 2015; Reinsalu et al., 2019). 
Table 3

Percentages of $\mathrm{X}$ - and $\mathrm{Y}$-chromosome bearing spermatozoa in unsorted and $\mathrm{X}$-enriched semen samples

\begin{tabular}{|c|c|c|c|c|c|}
\hline \multirow[t]{2}{*}{ Type of sample } & & \multicolumn{2}{|c|}{ X-bearing spermatozoa } & \multicolumn{2}{|c|}{ Y-bearing spermatozoa } \\
\hline & & Mean \pm S.E. & Range & Mean \pm S.E. & Range \\
\hline \multirow[t]{8}{*}{ Unsorted semen } & 1 & $50.74 \pm 2.52$ & $47.44-54.21$ & $49.24 \pm 2.52$ & $45.79-52.55$ \\
\hline & 2 & $49.03 \pm 3.23$ & $46.74-51.31$ & $50.97 \pm 3.23$ & $48.68-53.25$ \\
\hline & 3 & $49.41 \pm 4.23$ & $45.94-54.11$ & $50.59 \pm 4.22$ & $45.88-54.05$ \\
\hline & 4 & $49.76 \pm 0.62$ & $49.31-50.20$ & $50.24 \pm 0.622$ & $49.79-50.68$ \\
\hline & 5 & $50.96 \pm 2.94$ & $48.87-53.04$ & $49.04 \pm 2.94$ & $46.95-51.12$ \\
\hline & 6 & $53.54 \pm 4.47$ & $50.37-56.70$ & $46.45 \pm 4.47$ & $43.29-49.62$ \\
\hline & 7 & $48.27 \pm 2.95$ & $46.18-50.36$ & $51.73 \pm 2.95$ & $49.63-53.81$ \\
\hline & Overall & $50.24 \pm 0.65$ & $45.94-56.70$ & $49.75 \pm 0.62$ & $43.29-54.05$ \\
\hline \multirow[t]{5}{*}{ X-enriched semen } & 1 & $93.53 \pm 0.54$ & $92.52-94.37$ & $6.47 \pm 0.54$ & $5.63-7.48$ \\
\hline & 2 & $92.73 \pm 0.73$ & $91.29-93.66$ & $7.27 \pm 0.73$ & $6.34-7.48$ \\
\hline & 3 & $90.79 \pm 0.52$ & $89.86-91.69$ & $9.21 \pm 0.52$ & $8.31-10.14$ \\
\hline & 4 & $90.14 \pm 0.26$ & $89.72-90.63$ & $9.86 \pm 0.26$ & $9.37-10.28$ \\
\hline & Overall & $91.80 \pm 0.79$ & 89.72 - 94.37 & $8.20 \pm 0.73$ & $5.63-10.28$ \\
\hline
\end{tabular}

To conclude, the sex determination in bovine unsorted semen samples was performed successfully with SYBR Green fluorescent dye. The SYBR Green real time quantitative PCR is a rapid and reliable technique in absolute quantification of sex ratio in bovine semen samples. This method is a valid tool for routine validation of high number of sorted semen samples, determination of sex ratio in pooled semen samples and can also be used for the validation or calibration of other related techniques.

\section{Statements And Declarations}

\section{Acknowledgements:}

The financial support provided by Department of Animal Genetics and Breeding, Madras Veterinary College, Chennai is gratefully acknowledged.

Funding information: The authors declare that no funds and grants were received during the preparation of this manuscript.

Conflict of interest: The authors have no relevant financial or non-financial interests to disclose. 
Author's contribution: All authors contributed to the study conception and design. Study conduction and data acquisition was done by Vemula Harshini. Data analysis and interpretation was done by Vemula Harshini and C. Jeevan. The first draft of the manuscript was written by Vemula Harshini. Manuscript critical review for important intellectual content was done by S.M.K. Karthickeyan, K.G. Tirumuruggan and P. Kumarasamy. All authors read and approved the final manuscript.

Availability of data and material: The data set generated and analyzed during the current study are not publicly available due to confidential reasons, but are available from the corresponding author on reasonable request.

Ethical statement: The manuscript does not contain clinical studies or patient data

Consent to participate: Not applicable

Consent for publication: Not applicable

Code availability: Not applicable

\section{References}

1. Colley, A., Buhr, M. and Golovan, S.P., 2008. Single bovine sperm sex typing by amelogenin nested PCR. Theriogenology, 70(6), 978-983.

2. Habermann, F.A., Winter, A., Olsaker, I., Reichert, P. and Fries, R., 2005. Validation of sperm sexing in the cattle (Bos taurus) by dual colour fluorescence in situ hybridization. Journal of Animal Breeding and Genetics, 122(suppl.1), 22-27.

3. Hamilton, C. K., Favetta, L. A., Di Meo, G. P., Floriot, S., Perucatti, A., Peippo, J., Kantanen, J., Eggen, A., lannuzzi, L. and King, W. A., 2009. Copy number variation of testis-specific protein, Y-encoded (TSPY) in 14 different breeds of cattle (Bos taurus). Sexual Development, 3(4), 205-213.

4. Johnson, L. A., 2000. Sexing mammalian sperm for production of offspring: the state of the art. Animal Reproduction Sciences, 60-61, 93-107.

5. Johnson, L. A., Flook, J.P. and Hawk, H.W., 1989. Sex pre selection in rabbits: live births from $X$ and $Y$ sperm separated by DNA and cell sorting. Biology of Reproduction, 41(2), 199-203.

6. Liang, X.W., Lu, Y.Q., Chen, M.T., Zhang, X.F., Lu, S.S., Zhang, M., Pang, C.Y., Huang, F.X. and Lu, K.H., 2008. In vitro embryo production in buffalo (Bubalus bubalis) using sexed sperm and oocytes from ovum pick up. Theriogenology, 69(7), 822-826.

7. Lu, Y.Q., Liang, X.W., Zhang, M., Wang, W.L., Kitiyanant, Y., Lu, S.S., Meng, B. and Lu, K.H., 2007. Birth of twins after in vitro fertilization with flow-cytometric sorted buffalo (Bubalus bubalis) sperm. Animal Reproduction Sciences, 100(1-2), 192-196.

8. Luna-Estrada, A.A., Vera-Avila, H.R., Mora, O., Anguiana-Serrano, B., Vasquez- Pelaez, C.G. and Shimada, A., 2006. Effect of pre-mating nutritional status in red deer (Cervus elaphus scoticus) hinds on the sex of their offspring. Small Ruminant Research<bi>,</bi> 65(1-2), 154-160. 
9. Maleki, A.F., Moussavi, A.H., Nassiri, M.R., Tahmoorespur, M. and Vakili, S.A., 2013. Introducing and validation of SYBR green real-time PCR method to determinate sex ratio in bovine semen. Animal Reproduction Sciences, 140(1-2), 1-6.

10. Maxwell, W.M.C., Evans, G., Hollinshead, F.K., Bathgate, R., De Graaf, S.P., Eriksson, B.M., Gillan, L., Morton, K.M. and O'Brien, J.K., 2004. Integration of sperm sexing technology into the ART toolbox. Animal Reproduction Sciences, 82-83, 79- 95.

11. Maya, O.I., Yamada, K., Hayakawa, H. and Suzuki, H., 2013. Sexing of dog sperm by fluorescence in situ hybridization. Journal of Reproduction and Development, 59(1), 92-96.

12. Parati, K., Bongioni, G., Aleandri, R. and Galli, A., 2006. Sex ratio determination in bovine semen: $A$ new approach by quantitative real time PCR. Theriogenology, 66(9), 2202-2209.

13. Pindaru, L., Balaci, I.M. and Groza, I.S., 2016. Sperm sexing technology-new directions in medicine.

14. <background-color:\#5B96A2;bu>Revista Romana de</background-color:\#5B96A2;bu><backgroundcolor:\#CCFF99;bu>Medicina de Laborator</background-color:\#CCFF99;bu>, 24(1), 111-121.

15. Piumi, F., Vaiman, D., Cribiu, E.P., Guerin, B. and Humblot, P., 2001. Specific cytogenetic labeling of bovine spermatozoa bearing $\mathrm{X}$ or $\mathrm{Y}$ chromosomes using fluorescent in situ hybridization (FISH). Genetics Selection Evolution, 33(1), 89-98.

16. Reinsalu, O., Scheler, O., Mikelsaar, R., Mikelsaar, A.V., Hallap, T., Jaakma, U., Padrik, P., Kavak, A., Salumets, A. and Kurg, A., 2019. A dual colour FISH method for routine validation of sexed Bos taurus semen. BMC Veterinary Research, 15(1), 104-111.

17. Rens, W., Yang, F., Welch, G., Revell, S., O'Brien, P.C.M., Solanky, N., Johnson, L.A. and Smith, M.A.F., 2001. An XY paint set and sperm FISH protocol that can be used for validation of cattle sperm separation procedures. National agricultural library, United states. Reproduction, 121(4), 541-546.

18. Révay, T., Kovács, A., Rens, W. and Gustavsson, I., 2002. Simultaneous detection of viability and sex of bovine spermatozoa. Reproduction, Fertility and Development<bi>,</bi> 14(6), 373-376.

19. Rosenfeld, C.S. and Roberts, R.M., 2004. Maternal diet and other factors affecting offspring sex ratio: A Review. Biology of Reproduction, 71(4), 1063-1070.

20. Seidel, G.E.Jr., 2012. Sexing mammalian sperm-where do we go from here? Journal of Reproduction and Development, 58(2), 505-509.

21. Seidel, G.E. Jr. and Garner, D.I., 2002. Current status of sexing mammalian spermatozoa. Reproduction, 124(6), 733-43.

22. Tan, Y. J., Mahanem, M.N. and Somarny, W.W.M.Z., 2015. SYBR® green quantitative PCR for sex determination of bovine spermatozoa. Journal of Tropical Agriculture and Food Science, 43(1), 2939.

23. Welch, G.R. and Johnson, L.A., 1999. Sex pre selection: laboratory validation of the sperm sex ratio of flow sorted X-and Y-sperm by sort reanalysis for DNA. Theriogenology, 52(8), 1343-1352.

24. Whyte, J.J., Roberts, R.M. and Rosenfeld, C.S., 2007. Fluorescent in situ hybridization for sex chromosome determination before and after fertilization in mice. Theriogenology, 67(5), 1022-1031. 
25. Yadav, S. K., Gangwar, D.K., Singh, J., Tikadar, C.K., Khanna, V.V., Saini, S., Dholpuria, S., Palta, P., Manik, R.S., Singh, M.K. and Singla, S.K., 2017. An immunological approach of sperm sexing and different methods for identification of $X$-and Y-chromosome bearing sperm. Veterinary World, 10(5), 498-504.

26. Yan, J., Feng, H.L., Chen, Z.J., Hu, J., Gao, X. and Qin, Y., 2006. Influence of swim-up time on the ratio of $X$ and $Y$ bearing spermatozoa. European Journal of Obstetrics \& Gynecology and Reproductive Biology 129(2), 150-154.

\section{Figures}
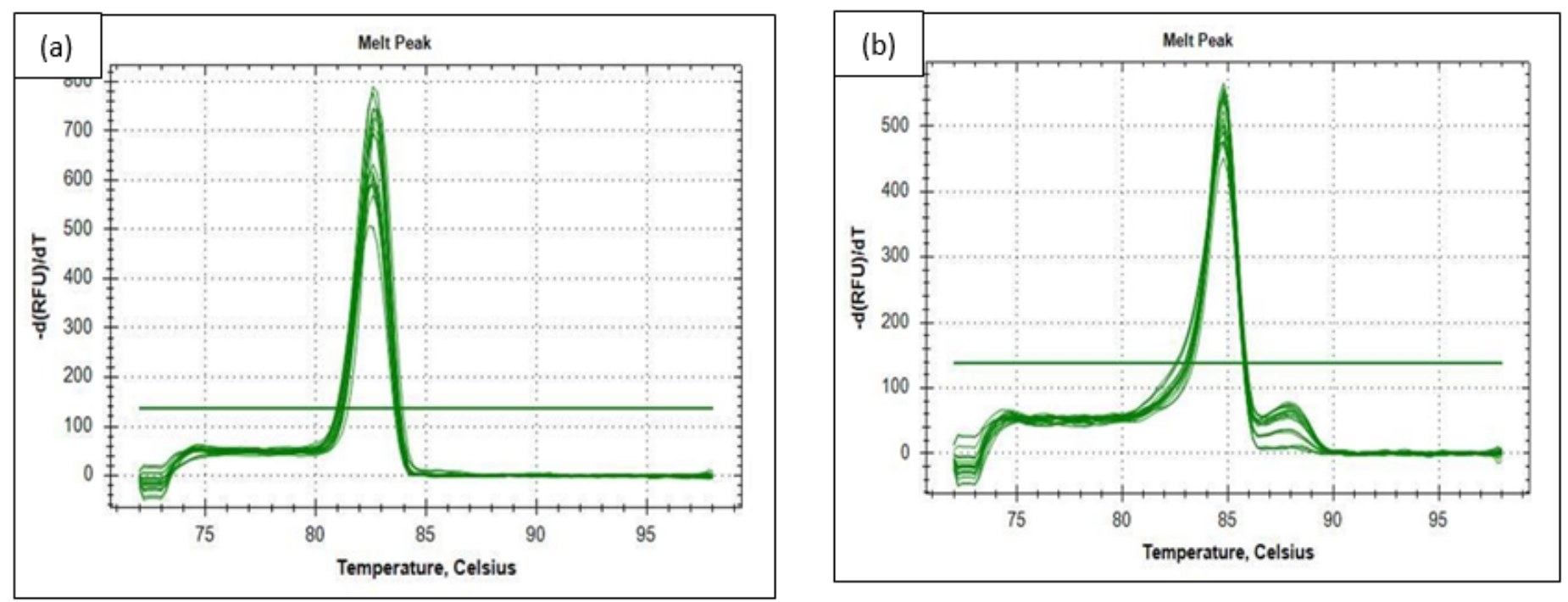

Figure 1

Melting curve of (a) PLP gene $\left(82.20^{\circ} \mathrm{C}\right)$ and (b) SRY gene $\left(84.40^{\circ} \mathrm{C}\right)$
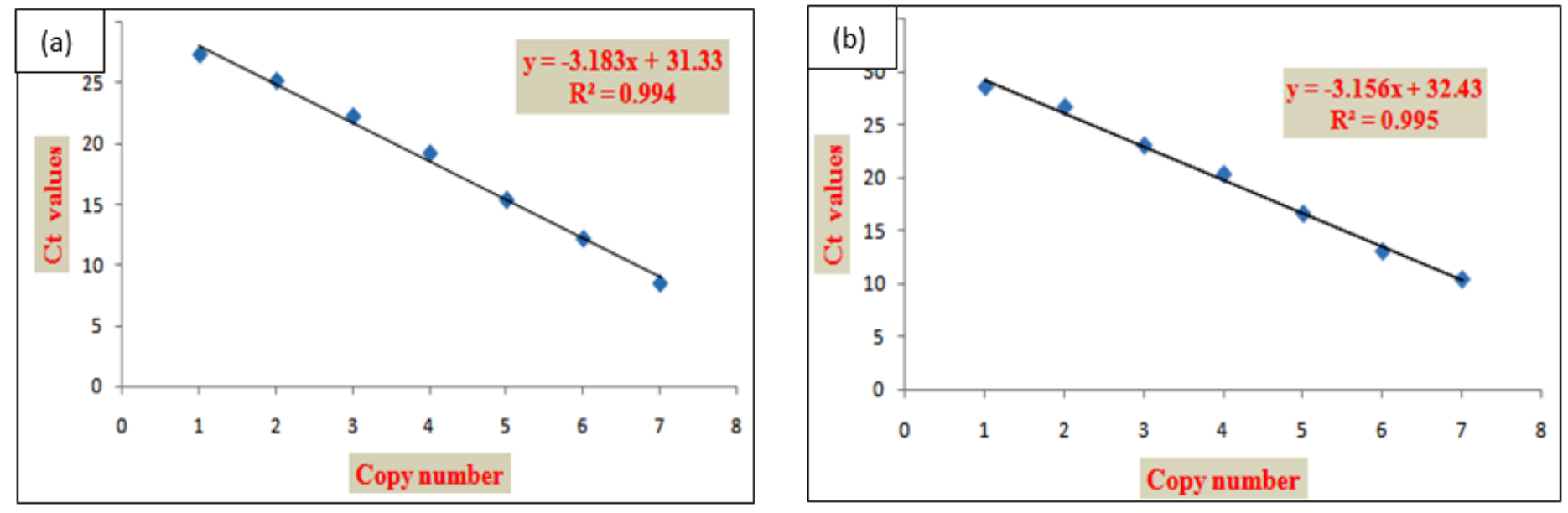

Figure 2 
Standard curve of (a) PLP and (b) SRY genes

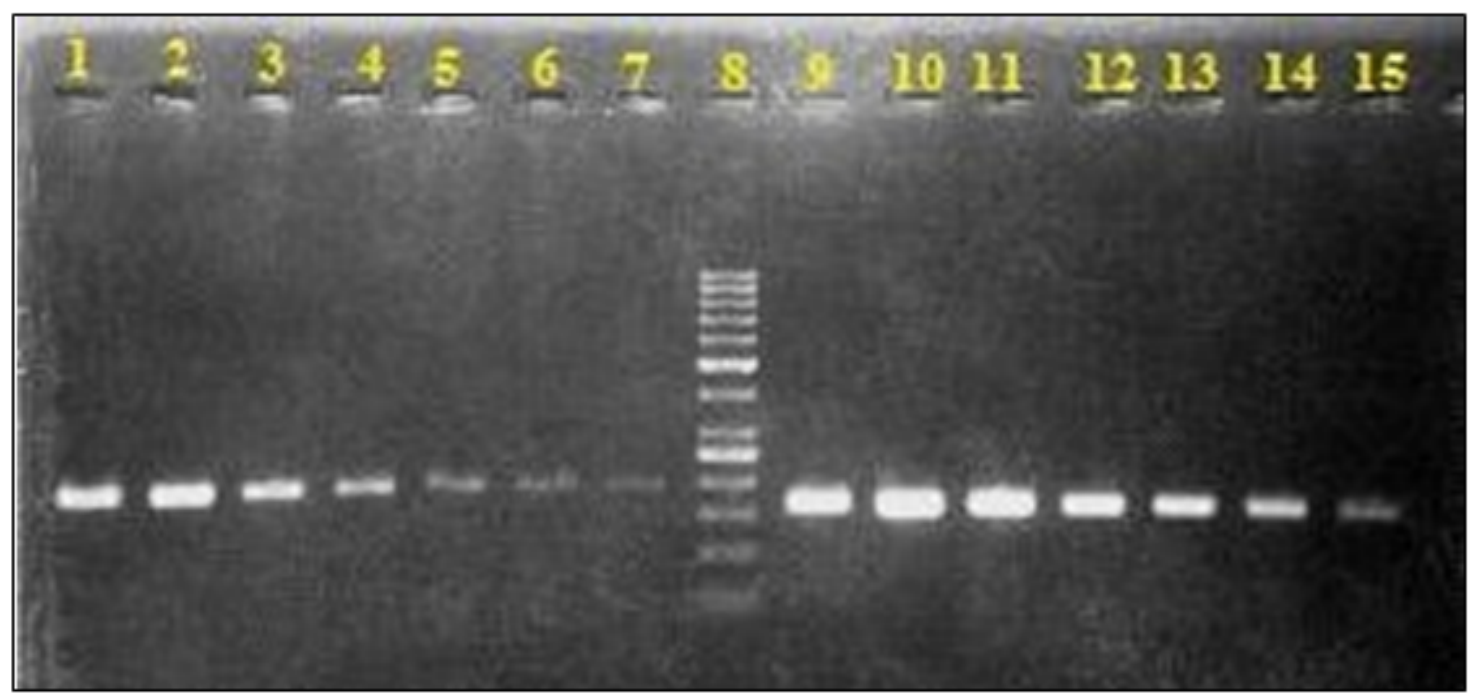

\section{Figure 3}

Gel electrophoresis ( $2 \%$ agarose) revealinging gradual reduction in the intensity of amplicons upon serial dilutions for PLP and SRY genes (Lanes 1-7: PLP gene dilutions from $1 \times 10^{8}$ to $1 \times 10^{2}$; Lane 8: 50 bp marker; Lanes 9-15: $S R Y$ gene dilutions from $1 \times 10^{8}$ to $1 \times 10^{2}$ ) 